\title{
VERIFICAÇÃO DA APLICABILIDADE E COMPORTAMENTO DO INDICE DE LOWELL SMITH, PARA ESTIMAR AS NECESSIDADES DE TRATAMENTO GENGIVAL (1)
}

Cardoso, G. M. - Verificação da aplicabilidade e comportamento do índice de Lowell Smith, para estimar as necessidades de tratamento gengival. Rev. Saúde públ., S. Paulo, 3(2):117-132, dez. 1969.

RESUMo - Foi realizado um estudo de calibração em estudantes do "Colégio Estadual Carlos Maximiliano Pereira dos Santos", em São Paulo, Brasil, aplicando o Indice GTI de Lowell Smith, que estima necessidade de tratamento gengival. Foi testado o fndice GTI e verificado a sua aplicabilidade e comportamento. A percentagem de concordância encontrada entre examinadores foi de $70 \%$. Para o examinador A encontrou-se $76 \%$ de concordância e para o examinador $\mathrm{B}, 73 \%$.

\section{I N T R O D U C $\mathrm{A} O$}

Smith ${ }^{25}$ (1966) elaborou um Indice denominado GTI, nos Estados Unidos, que estima necessidades de tratamento gengival e necessidades de mão-de-obra. Cada uma das categorias propostas pelo fndice sugere tratamento clínico e, também, fatôres educativos a serem ensinados aos pacientes. $\mathbf{O}$ ideal seria que fôsse utilizado em indivíduos que ainda não tivessem sofrido considerável perda de suporte periodontal, nem tivessem muitos dentes perdidos por cárie. Ambos os fatôres complicam o tratamento indicado, para conservar os tecidos periodontais remanescentes. $O$ autor, ao elaborar o fndice, não pretendeu substituir métodos convencionais de diagnóstico adequados para estimar necessidades de tratamento de um indivíduo. Quando se utiliza o fndice GTI, as discordâncias a respeito da estimativa de necessidades de tratamento gengival para o indivíduo pode ser na ordem de $15 \%$ a $20 \%$. No estudo realizado nos Estados Unidos por Lowell W. Smith, para testar o seu fndice, foram utilizados rapazes pertencentes ao Instituto Federal Correcional de Eglewood, Colorado.

O objetivo dêste trabalho foi testar o Indice e verificar a sua aplicabilidade e comportamento através de resultados obtidos de um estudo de calibração. Pa. ra isto utilizamos rapazes, estudantes do Curso Noturno do "Colégio Estadual Carlos Maximiliano Pereira dos Santos (São Paulo, 1967).

Recebido para publicação em 30-3-1969.

(1) Trabalho apresentado à Faculdade de Higiene e Saúde Pública para obtenção do título de Mestrado.

(2) Da Cadeira de Odontologia Social do Instituto de Higiene e Medicina Preventiva da Universidade Federal. Santa Maria, R. S. - Brasil. 
CARDOSO, G. M. - Verificaçâo da aplicabilldade e comportamento do indice de Lowell Smith, para estimar as necessidades de.. Rev. Saúde públ., S. Paulo, 3(2):117-132, dez. 1969.

\subsection{Epidemiologia - Doença periodon. tal como problema de Saude Pública}

As periodontopatias figuram entre as doenças mais comuns do gênero humano.

Muitos autores têm evidenciado a existência da doença periodontal, parecendo não existir país algum do mundo, livre desta enfermidade. Massler, Shour \& ChoPRA ${ }^{15}$ (1950), Marshall-Day ${ }^{14}$ (1951), RuSSELl ${ }^{21}$ (1956), RAMFJoRd ${ }^{18}$ (1959), Lövdal et alii ${ }^{13}$ (1961), Greene ${ }^{6}$ (1963), Greene \& Vermilition ? (1964), Lilienthal, Armena \& Gregory 11 (1965), através de estudos epidemiológicos demonstraram a prevalência, a incidência e a severidade da doença periodontal.

Marshall-Day ${ }^{14}$ (1951) e GreEne ${ }^{4}$ (1959) citam os antigos egípcios e gregos, como portadores do problema periodontal, informando também que Pierre Fauchard, em 1680, já escrevia sôbre a doença. A nova era das periodontopatias caracterizou-se por uma metodologia científica, tendo alcançado rápida expansão, a partir de 1951.

Não é suficiente ter-se a noção de que a doença periodontal é difundida. E importante saber como se expande e com que severidade. A função fundamental da Epidemiologia, segundo ENGLANDER ${ }^{3}$ (1962) é: "determinar a ocorrência e distribuição da doença na coletividade, em condiçoes tais que permitam definir problemas e formular objetivos".

RUSSELl ${ }^{19}$ (1967), afirma ser a doença periodontal tão importante quanto a cárie dental, como problema de saúde pública. Pesquisas epidemiológicas realizadas por Levine ${ }^{10}$ (1965) nos falam da prevalência, da severidade e dos povos que possuem doença periodontal.

Com os conhecimentos adquiridos poderíamos planejar um ataque à doença periodontal $e$, ao mesmo tempo, testar a eficiência de novos métodos de tratamento e de contrôle.

O profissional de saúde pública está interessado na prevalência, incidência $e$ severidade de uma determinada doença, dentro de uma comunidade.
Pelton, Pennel \& Druzina ${ }^{17}$ (1954), analisando 225.000 fichas de tratamento odontológico de beneficiários do Serviço de Saúde Pública dos Estados Unidos, verificaram que a causa da mortalidade dental para pacientes até 35 anos foi a cárie $e$, que acima desta idade, a doença periodontal representou a causa principal da perda de dentes.

Greene (1963), no estudo realizado na República do Equador e em Montana, Estados Unidos, demonstrou claramente a correlação existentè entre doença periodontal e higiene oral deficiente.

Russell ${ }^{20}$ (1965), examinando mais de 21.000 pessoas em regiões do Alaska, Etiópia, Equador, Vietnam do Sul, Chile, Colômbia e Líbano, em relação à higiene oral e doença periodontal, chegou à conclusão de que sexo, educação, raça e nível sócio-econômico têm papel insignificante em relação à importância da higiene oral e à idade.

LiNN ${ }^{12}$ (1965) diz "ser função da profissão odontológica, entender saúde oral como odontologia preventiva". Por esta razão, existem amplos motivos para se educar o público, no assunto: - Advirão daí os benefícios de uma boa profilaxia oral.

\subsection{Métodos para medir doença perio- dontal - Indices. Calibraçẫo de examinadores}

Para se levar a bom têrmo um estudo epidemiológico, é necessário utilizar índices com o objetivo de medir a presença e a severidade das lesóes periodontais.

Segundo a OMS ${ }^{16}$ (1961), os índices de população para as periodontopatias são cifras que permitem avaliar o estado de uma coletividade, sôbre uma escala graduada cujos limites superior e inferior estão bem definidos, permitindo compará-los com os de outras comunidades classificadas, com os mesmos critérios e mé. todos.

Os dados epidemiológicos devem ser obtidos, de acôrdo com RAMF JoRD ${ }^{18}$ (1959), através de sistemas numéricos com os 
CARDOSO, G. M. - Verificação da aplicabilidade e comportamento do indice de Lowell Smith, para estimar as necessidades de. Rev. Saúde públ., S. Paulo, 3(2):117-132, dez. 1969.

quais se possa computar um índice. Este necessita ser quantitativo, porque deve indicar a severidade da doença, com uma precisão razoável, permitindo assim, uma análise estatística.

A escolha de um índice, em qualquer ocasião, em relação às doenças periodontais, deve ser feita levando-se em conta o gênero de informação que se quer; o número de pessoas que irá submeter-se ao exame; a qualidade e a quantidade de material que se poderá utilizar com referência às circunstâncias e ao local onde se realizará o estudo. Torna-se necessário despertar a atenção para o fato de que - objetivo fundamental de todos os índices é classificar o status da doença periodontal de um indivíduo ou de uma população, de forma a levar em consideração tanto a prevalência como a severidade da lesão. Dentro dêstes limites, os índices podem variar consideràvelmente. De acôrdo com VIEGas (1965) e WaErhaug ${ }^{27}$ (1966), citaremos os indices mais comumente usados na atualidade.

\section{Indice Gengival de Schour e Massler (P.M.A.)}

Representa provàvelmente o primeiro esfôrço para designar, com sucesso, um sistema numérico, para medir condições periodontais. $\mathbf{E}$ indicado em estudos para verificar a ação de certos agentes em relação à gengiva. A calibração não é fácil, principalmente, no que se refere aos graus zero e um. Limita-se ao estudo das gengivites.

\section{Indice Periodontal de Russell (PI)}

E indicado para avaliar os aspectos quantitativos e qualitativos da doença periodontal. Segundo o próprio Russell ${ }^{21}$ (1956), êste índice pode ser aplicado ràpidamente, com um mínimo de equipa. mento. A calibração dos examinadores é relativamente fácil. $\mathrm{O}$ método apenas não avalia a perda óssea em jovens. Permite, todavia, distinguir fàcilmente os esta- dos iniciais da doença, aos mais avançados, sendo um dos índices mais amplamente utilizados até o presente momento.

\section{Indice de Doença Periodontal de Ramfjord (PDI)}

Em princípio, êste índice foi introduzido por RAMFJoRD ${ }^{18}$ (1959). É indicado quando existir interêsse em avaliar-se a perda óssea em jovens. Pode ser analisado pelos métodos estatísticos modernos. Como desvantagem, requer muita habilidade do examinador, e a calibração é difícil.

\section{Indice de Retração Gengival de Stahl e Morris}

Este é um índice que pode ser aplicado por examinadores sem experiência, sendo um índice simples e rápido.

Quanto à calibração, a variabilidade entre examinadores pode ser reduzida ao mínimo. Em pessoas com tártaro sub gengival denso, a sua exequibilidade seria mais difícil.

\section{Indice Gengival de Löe e Silness}

Baseia-se nos mesmos princípios do indice P.M.A.

E indicado por uma escala que vai de zero a três. Para experiências clínicas, êste índice é muito sensível e existe uma boa concordância com o fndice Periodontal.

\section{Indice de Higiene Oral de Greene e Vermillion (I.H.O.)}

Este fndice surgiu do desenvolvimento adicional do índice de Ramfjord. Foi primeiramente descrito, em 1960, sendo modificado, posteriormente, pelos mesmos autores $^{8}$ (1964) passando a chamar-se Indice de Higiene Oral Simplificado de Greene e Vermillion.

Indicações dêste índice: quando houver interêsse em observar a relação de indutos e tártaros com a doença periodontal, 
CARDoso, G. M. - Verificação da aplicabilidade e comportamento do índice de Lowell Smith, para estimar as necessidades de.. Rev. Saúde públ., S. Paulo, 3(2):117-132, dez. 1969.

sua epidemiologia, bem como os resultados a curto e a longo prazo de programas dentais de educação sanitária. É um índice rápido com critérios bem definidos. Entre os examinadores as diferenças são moderadas.

\section{Indice G.T.I. de Lowell Smith (1966)}

Êste índice estima as necessidades de tratamento gengival e baseia-se na presença de espessos ou leves depósitos de cálculos, indutos e manchas extrínsecas nos dentes.

Este índice é indicado para identificar necessidades de tratamento gengival em jovens onde ainda não houve perda óssea. Baseia-se na presença de depósitos dentais, sem levar em consideração mudan. ças de coloração, contôrno e consistência da gengiva.

As vantagens de seu uso, são as seguintes:

a) mais provável que a discordância entre examinadores ocorra devido à presença de depósitos dentais, do que em relação à inflamação;

b) o método pode ser usado em qualquer paciente independentemente da côr da pele, sendo difícil detectar mudanças de coloração em pacientes com as gengivas muito pigmentadas;

c) ainda que os sinais clínicos de inflamação não possam ser detectados, torna-se mais fácil ao profissional recomendar a remoção de depósitos dentais.

$O$ índice GTI é indicado em programas de odontologia preventiva como um método para estimar necessidades de tratamento gengival e, serve ainda, para avaliar necessidades de mão-de-obra.

Na Tabela 1 estão distribuídas as categorias e códigos do índice, além do tratamento clínico e educação sanitária que deverão ser ministrados ao indivíduo, dentro de cada categoria.

Com a intenção de simplificar, passaremos a usar a sigla INTG para o índice GTI, significando Indice de Necessidade de Tratamento Gengival.

T A B E I A I

Critérios para Classificação do INTG

\begin{tabular}{|c|c|c|c|}
\hline $\begin{array}{l}\text { Catego- } \\
\text { rias }\end{array}$ & Condição & $\begin{array}{l}\text { Tratamento } \\
\text { Clínico }\end{array}$ & $\begin{array}{c}\text { Fatôres educativos a serem } \\
\text { ensinados aos pacientes }\end{array}$ \\
\hline I & $\begin{array}{l}\text { Não há presença de } \\
\text { cálculos ou mancha } \\
\text { extrínseca. } \\
\text { Indutos podem cobrir } \\
1 / 3 \text { da superfície ex- } \\
\text { posta de um ou mais } \\
\text { dentes. }\end{array}$ & Nenhum. & Nenhum. \\
\hline II & $\begin{array}{l}\text { Não há presença de } \\
\text { cálculos. Manchas ex- } \\
\text { trinsecas estão presen- } \\
\text { tes e os indutos podem } \\
\text { cobrir mais do que } 1 / 3 \\
\text { da superfície de um } \\
\text { ou mais dentes. }\end{array}$ & $\begin{array}{l}\text { 1. Polimento da co- } \\
\text { roa. } \\
\text { 2. Polimento inter- } \\
\text { proximal. }\end{array}$ & $\begin{array}{l}\text { 1. Efeitos da higiene oral } \\
\text { individual para evitar a } \\
\text { deposiçăo de novos in- } \\
\text { dutos. } \\
\text { 2. Papel dos indutos no } \\
\text { inicio da doença gengi- } \\
\text { val. } \\
\text { 3. Alimentos com efeitos: } \\
\text { de autolimpeza nos den- } \\
\text { tes, comparados com } \\
\text { aquêles que aderem aos: } \\
\text { dentes. }\end{array}$ \\
\hline
\end{tabular}


CARDOSO, G. M. - Verificação da aplicabilidade e comportamento do índice de Lowell Smith, para estimar as necessidades de.. Rev. Saúde públ., S. Paulo, 3(2):117-132, dez. 1969.

\begin{tabular}{c|c|c|c}
\hline $\begin{array}{c}\text { Catego- } \\
\text { rias }\end{array}$ & Condicáo & $\begin{array}{c}\text { Tratamento } \\
\text { Clínico }\end{array}$ & $\begin{array}{c}\text { Fatôres educativos a serem } \\
\text { ensinados aos pacientes }\end{array}$ \\
\hline & & &
\end{tabular}
oral pessoal como auxílio na prevenção.

5. Razões da dificuldade em remover manchas extrinsecas, durante a profilaxia oral.

\begin{tabular}{|c|c|c|}
\hline III & $\begin{array}{l}\text { Presença de cálculos } \\
\text { supragengivais, mas } \\
\text { não subgengivais. } \\
\text { Indutos e manchas po- } \\
\text { dem estar presentes. }\end{array}$ & $\begin{array}{l}\text { 1. Remocão de tár- } \\
\text { taro coronário. } \\
\text { 2. Polimento coroná- } \\
\text { rio. } \\
\text { 3. Polimento inter- } \\
\text { proximal. }\end{array}$ \\
\hline IV & $\begin{array}{l}\text { Cálculo subgengival, } \\
\text { cobrindo menos do que } \\
1 / 3 \text { do dente no sen- } \\
\text { tido horizontal. Cál- } \\
\text { culos supragengivais, } \\
\text { indutos e manchas po- } \\
\text { dem estar presentes. }\end{array}$ & $\begin{array}{l}\text { 1. Remoção de tár- } \\
\text { taro coronário. } \\
\text { 2. Remocão de tár- } \\
\text { taro subgengival. } \\
\text { 3. Raspagem radicu- } \\
\text { lar. } \\
\text { 4. Polimento coroná- } \\
\text { ró. } \\
\text { 5. Polimento inter- } \\
\text { proximal. } \\
\text { 6. Podem ser execu- } \\
\text { tadas curetagens } \\
\text { nos tecidos moles. }\end{array}$ \\
\hline $\mathrm{V}$ & $\begin{array}{l}\text { Calculos subgengivais, } \\
\text { cobrindo mais do que } \\
1 / 3 \text { da superficie den- } \\
\text { tal no sentido hori- } \\
\text { zontal. } \\
\text { Cálculos supragengi- } \\
\text { vais, indutos e man- } \\
\text { chas podem estar pre- } \\
\text { sentes. }\end{array}$ & $\begin{array}{l}\text { 1. Remoção de tár- } \\
\text { taro coronário. } \\
\text { 2. Remocão de tár- } \\
\text { taro subgengival. } \\
\text { 3. Raspagem radicu- } \\
\text { lar. } \\
\text { 4. Polímento coroná- } \\
\text { rio. } \\
\text { 5. Polimento inter- } \\
\text { proximal. }\end{array}$ \\
\hline
\end{tabular}

1. Efeito de cálculo nos tecidos periodontais e saúde geral na bôca.

2. O que é cálculo e como se forma.

3. Importância da visita periódica ao dentista para a remoção de cálculos e manchas.

4. A prática da higiene oral pessoal que o paciente pode realizar para prevenir o acúmulo de cálculos.

1. Consequiências dos cálculos, afim de justificar o procedimento minucioso de sua remocão por pessoal profissional.

2. A importância da visita periodica ao dentista para a remoção de cálculos e manchas.

3. A prática da higiene oral Individual que a paciente pode realizar para prevenir acúmulo de cálculos.

4. Interrelação do mecanismo de autolimpeza (dieta), a prática da higiene oral individual, e a profilaxia oral na prevenção da formação de depósitos nos dentes.

1. Efeitos da doença da gengiva e do periodonto na saúde geral.

2. A prática da higiene oral individual que o paciente pode realizar para prevenir acúmulo de cálculos.

3. A importância das visitas perídicas ao den- 
CARDOSO, G. M. - Verificação da aplicabilidade e comportamento do indice de Lowell Smith, para estimar as necessidades de. Rev. Saúde públ., S. Paulo, 3(2):117-132, dez. 1969.

\begin{tabular}{|c|c|c|c|}
\hline $\begin{array}{l}\text { Catego- } \\
\text { rias }\end{array}$ & Condição & $\begin{array}{l}\text { Tratamento } \\
\text { Clinico }\end{array}$ & $\begin{array}{c}\text { Fatôres educativos a serem } \\
\text { ensinados aos pacientes }\end{array}$ \\
\hline $\mathrm{V}$ & & $\begin{array}{l}\text { 6. Podem ser execu- } \\
\text { tadas curetagens } \\
\text { nos tecidos moles. } \\
\text { 7. Alivio da oclusão } \\
\text { traumática. }\end{array}$ & $\begin{array}{l}\text { tista para a remocão de } \\
\text { cálculos e manchas. } \\
\text { 4. Interrelação do meca- } \\
\text { nismo de auto limpeza } \\
\text { (dieta), a prática de } \\
\text { higiene oral individual, } \\
\text { a profilaxia oral na } \\
\text { prevenção da formação } \\
\text { de depósitos nos dentes. }\end{array}$ \\
\hline VI & $\begin{array}{l}\text { Presenca de hipertro- } \\
\text { flas (espessamento do } \\
\text { tecido gengival, co- } \\
\text { brindo mais do que } \\
1 / 3 \text { da coroa anatô- } \\
\text { mica dos dentes). } \\
\text { Recessão, expondo } \\
\text { mais do que } 3 \mathrm{~mm} \text { da } \\
\text { superficie radicular; } \\
\text { fissura do tecido gen- } \\
\text { gival e formação de } \\
\text { bôlsas periodontais. }\end{array}$ & $\begin{array}{l}\text { Refere-se a den- } \\
\text { tistas especialistas } \\
\text { em terapêutica pe- } \\
\text { riodontal. }\end{array}$ & $\begin{array}{l}\text { 1. Pode incluir todos os } \\
\text { fatôres educacionais } \\
\text { acima descritos. }\end{array}$ \\
\hline
\end{tabular}

Smith ${ }^{25}$ (1966) usa 14 dentes para estimar as necessidades de tratamento gengival, assim distribuídos:

\begin{tabular}{l|l|l}
\hline \multicolumn{1}{c}{ Dente } & $\begin{array}{c}\text { Cálculo } \\
\text { Induto } \\
\text { Mancha extrínseca }\end{array}$ & Superficie \\
\hline $\begin{array}{l}\text { 1.0 Molar superior esquerdo } \\
\text { nino a canino) }\end{array}$ & Cálculo e induto & Vestibular \\
$\begin{array}{l}\text { 1.0 Molar superior direito } \\
\begin{array}{l}\text { Bateria labial inferior (de ca- } \\
\text { nino a canino) }\end{array}\end{array}$ & Induto & Vestibular \\
$\begin{array}{l}\text { Bateria labial inferior (de ca- } \\
\text { nino a canino) }\end{array}$ & Cálculo & Vestibular \\
\hline
\end{tabular}


CARDOSo, G. M. - Verificação da aplicabilidade e comportamento do índice de Lowell Smith, para estimar as necessidades de. Rev. Saúde públ., S. Paulo, 3(2):117-132, dez. 1969.

De acôrdo com W AERHAUg ${ }^{27}$ (1966), a calibração utilizada em estudos epidemiológicos, significa seguir a mesma orientação dada por um examinador considerado padrão, qual seja aquêle que se supóe conhecer e utilizar corretamente os métodos e critérios.

A calibração é absolutamente necessária e imprescindível em estudos epidemio. lógicos. Mesmo o mais experimentado pesquisador poderá discordar consigo mesmo, quando examina a mesma pessoa em duas diferentes ocasiōes.

Baseados na análise da variabilidade intra-examinadores, documentada durante - Estudo Pilôto Longitudinal de Calibração sôbre Periodontopatias no Oregon foram estabelecidos padróes a respeito da consistência de examinadores em relação a induto, cálculo, gengivite e medida de bôlsa periodontal. Estes padrões deverão ser alcançados pelo examinador, antes que êle participe do estudo pròpriamente dito. Após uma sessão de treinamento e discussões, e quando os examinadores se sentirem confiantes de que possam atingir os padrões estabelecidos, uma sessão prática de calibração deverá ser realizada. Caso os examinadores atinjam os padrōes estabelecidos, serão considerados aptos a participar do estudo. Em caso contrário, novas discussōes de critérios e práticas adicionais deverão ser programadas.

Os padrões propostos para as várias fases do exame, conforme o Estudo Pilôto Longitudinal de Calibração de Oregon, são os seguintes:

$1 .^{\circ}$ exame - induto, $70 \%$; cálculo supragengival, $90 \%$; e cálculo infragengival, $75 \%$.

$2:^{\circ}$ exame (reexame) - induto, $82 \%$; cálculo supragengival, $94 \%$; e cálculo infragengival, $83 \%$.

\section{MATERIAL E METODOS}

Foram examinados 93 estudantes do sexo masculino de 14 a 21 anos de idade e matriculados no Curso Noturno do Colégio Estadual Carlos Maximiliano $\mathrm{Pe}$ - reira dos Santos (Sáo Paulo). O material utilizado, para cada uma das equipes, foi o seguinte: quatro cadeiras comuns, uma mesa auxiliar, um jôgo de lâmpadas tipo Burton, dez espelhos bucais e 10 sondas exploradores $n .^{\circ} 5$. Ainda se utilizou merthiolate para assepsia do instrumental. Os resultados foram anotados em fichas.

Os componentes das equipes foram submetidos a uma calibração prévia, para que se familiarizassem com indutos, cálculos supra e sub gengivais. Para isso sortearam-se 30 estudantes que foram posteriormente eliminados do estudo pròpriamente dito.

Foram sorteados 93 estudantes, dentro do grupo etário de 14 a 21 anos, para testar a aplicabilidade e comportamento do fndice INTG. Isto foi feito verificando-se através da calibração intra e entre examinadores, a categoria à qual os pacientes seriam classificados após os exames.

A verificação para o êrro entre examinadores foi prèviamente fixado como o primeiro intra examinadores. Dos $93 \mathrm{ra}$ pazes examinados, foram sorteados 30 para cada examinador. Este exame foi fixado como o segundo intra com a finalidade de tabulação e posterior análise dos dados.

Formaram-se duas equipes constituídas cada uma de um examinador e um ano. tador. $\mathrm{O}$ monitor, comum às duas equipes, foi um funcionário do próprio Colégio onde se realizou o estudo. As duas equipes localizaram-se na mesma sala, durante todo o período dos exames.

Os estudantes entravam na sala, em grupus de quatro, sentando-se em cadeiras comuns. $O$ instrumental utilizado foi sempre o mesmo. Os examinados foram submetidos ao seguinte método de exame:

$O$ estudante 1 foi examinado pelo examinador $\mathrm{A}$;

$O$ estudante 2 foi examinado pelo examinador $B$.

Logo após o primeiro exame, o estudante 2 foi reexaminado e conseqüente- 
CARDOSO, G. M. - Verificação da aplicabilldade e comportamento do índice de Lowell Smith, para estimar as necessidades de.. Rev. Saude puibl., S. Paulo, 3(2):117-132, dez. 1969.

mente reclassificado pelo examinador $A$. $\mathrm{O}$ estudante 1 , pelo examinador $\mathrm{B}$, e assim por diante.

Como já foi dito, o $20^{\circ}$ exame intra-examinador, assim fixado para efeitos de tabulação e análise dos dados, foi também realizado. Dessa maneira, obtivemos percentagens de discordâncias entre $e$ intra examinadores, quando se aplicou o indice INTG. As categorias e códigos utilizados para êste Indice já foram descritos anteriormente. Os critérios para reconhecimento de cálculos, indutos e manchas extrínsecas na calibração, foram os mesmos utilizados por GreENE \& VERMILLION ${ }^{8}$ (1964) :

\section{Induto}

É uma matéria mole, aderida à superfície dos dentes. Consiste em mucina, bactérias e alimentos. Pode ser de côr branca, verde ou laranja.

\section{Mancha extrinseca}

E uma fina camada de substância firmemente aderida à superfície do dente, mas que pode ser removida, raspando-se esta superfície com a ponta do explorador. A côr pode variar do prêto ao marrom escuro, verde ou alaranjado.

\section{Cálculo}

É um depósito de sais inorgânicos constituído primàriamente de carbonato e fosfato de cálcio, acrescido de restos de alimentos, bactérias e células epiteliais descamadas.

\section{Cálculo supragengival}

E usualmente branco ou marrom amarelado, depositando-se no sentido ocluso-gengival.

\section{Cálculo infragengival}

E usualmente de côr marrom claro ou prêto, devido à existência de pigmentos do sangue, depositando-se no sentido ocluso apical ao redor da região cervical do dente.

Para detectar cálculos e manchas extrínsecas, usou-se a parte terminal do explorador $n .^{\circ} 5$. Este, deslizava através das superfícies vestibulares ou linguais fazendo sentir ou não a presença de cálculos. A sondagem periodontal foi feita com o explorador n. 5 mas nenhum paciente foi colocado na categoria VI.

Nenhum caso de suspeita de distúrbios sistêmicos ou deficiências nutricionais foi encontrado. De acôrdo com o autor do fndice INTG, deveriam ser colocados na categoria VI, caso estivessem presentes.

Os segundos molares permanentes foram utilizados em caso de ausência dos primeiros molares. Um indivíduos só era examinado se tivesse, no mínimo, três dentes anteriores inferiores, e um primeiro ou segundo molar presentes.

$O$ índice INTG não nos fornece critérios em relação a:

a) dente erupcionado;

b) pacientes com peças protéticas, tais como pivôs e coroas de jaquetas;

c) pacientes com as superfícies dentais reduzidas em altura, por cáries ou trauma.

Observamos que nas categorias III, IV, V e VI não foi estabelecido, pelo autor, se as superfícies expostas foram de um ou mais dentes.

Por esta razão, decidimos:

a) que o critério de dente erupcionado utilizado seria o mesmo de GreEnE \& Vermillion $^{8}$ (1964);

b) considerar os pivôs e coroas de jaquetas, pois a higiene oral deficiente atua nestas peças protéticas;

c) não considerar as superfícies dentais reduzidas em altura por cáries ou trauma;

d) quanto às categorias III, IV, V e VI, considerar as superfícies expostas de 
CARDoso, G. M. - Verificação da aplicabilidade e comportamento do índice de Lowell Smith, para estimar as necessidades de.. Rev. Saúde públ., S. Paulo, 3(2):117-132, dez. 1969.

um ou mais dentes, da mesma forma que - autor considerou as I e II.

Os exames foram completados em média, em 2 minutos. $O$ tratamento estatístico levado a efeito foi o cálculo das percentagens de discordâncias entre e intra examinadores. Utilizamos ainda o intervalo de confiança de $95 \%$ para os resultados.

Não nos valemos do teste de diferença entre as duas proporções. Acreditamos não haver margem de comparaçáo entre os dados solicitados e os do autor do f́ndice INTG. Isto, porque, as amostras não foram semelhantes, originadas de populações diferentes, e também, porque os hábitos de escovação de dentes eram provàvelmente diferentes entre os grupcs tes. tados.

A nossa amostra provàvelmente constituiu-se de rapazes de uma escola públi. ca pertencentes a um nível sócio-econômico razoável e acima do médio, enquanto que Smith ${ }^{25}$ (1966), utilizou-se de rapazes de um Instituto Correcional.

\section{RESULTA D O S}

A distribuição dos estudantes, examinados segundo a idade, foi a seguinte: 14 anos - 9; 15 anos - $11 ; 16$ anos $19 ; 17$ anos $-12 ; 18$ anos $-10 ; 19$ anos $-12 ; 20$ anos $-11 ; 21$ anos 9.

O número de discordâncias intra examinadores, o número de dentes examinados e a percentagem, encontram-se na Tabela 2. As percentagens de discordâncias encontradas pelo examinador $\mathrm{A}$, na Tabela 3 .

As percentagens de discordância do examinador $B$ podem ser visualizadas na Tabela 4 .

O número de discordâncias e as percentagens entre examinadores foi, respectivamente, de 346 e $27,13 \%$ sôbre um total de 1.275 dentes examinados.
As percentagens de discordâncias encontradas para os examinadores, classificadas segundo as categorias do indice, está contido na Tabela 5 .

Os intervalos de confiança de $95 \%$ pa. ra as percentagens de discordâncias foram calculados. Obtiveram os seguintes resultados, utilizando-se a unidade-dente:

Para o êrro entre examinadores

$$
24,7 \%-29,5 \% \text {; }
$$

para o êrro intra examinador (A)

$$
14,9 \%-24,4 \% \text {; }
$$

para o êrro intra examinador (B)

$$
13,4 \%-20,5 \% \text {. }
$$

$\mathrm{O}$ número de indivíduos, classificados pelo examinador $A$, para exame e reexame, encontra-se na Tabela 6 . Os classificados pelo examinador $B$ nas categorias do fndice, podem ser visualizados na Tabela 7. Os classificados segundo os examinadores nas categorias do fndice, estão contidos na Tabela 8.

As percentagens de discordâncias intra examinadores, quando se utilizou a unidade-indivíduo, estão contidas na Tabela 9, enquanto que as de discordâncias entre examinadores estão na Tabela 10.

A percentagem de concordância entre examinadores, quando se utilizou a unidade-individuo, foi de $70 \%$, assim como as percentagens de concordâncias intra examinadores foram, respectivamente: para o examinador $\mathrm{A}=76 \%$; para o examinador $B=73 \%$ (Tabelas 6,7 e 8 ).

Os intervalos de confiança de $95 \%$ para as percentagens de concordâncias, intra e entre examinadores, também foram calculados obtendo-se os seguintes resultados:

Para os examinadores A e B $89 \%-59 \%$;

para o examinador $\mathbf{A}$ $79 \%-60 \%$;

para o examinador $\mathbf{B}$ $87 \%-53 \%$. 
CARDoso, G. M. - Verificação da aplicabilidade e comportamento do indice de Lowell Smith, para estimar as necessidades de.. Rev. Saúde públ., S. Paulo, 3(2):117-132, dez. 1969.

T A B E L A 2

Número de dentes examinados segundo os examinadores, número e percentagem de discordâncias

\begin{tabular}{c|c|c|c}
\hline $\begin{array}{c}\text { Examina- } \\
\text { dores }\end{array}$ & $\begin{array}{c}\text { N.o de dentes } \\
\text { examinados }\end{array}$ & $\begin{array}{c}\text { Número de } \\
\text { discordâncias }\end{array}$ & $\begin{array}{c}\text { Percentagem de } \\
\text { discordancia }\end{array}$ \\
\hline A & 407 & 76 & 18,67 \\
B & 417 & 71 & 17,02 \\
\hline Total & 824 & 147 & 17,84 \\
\hline
\end{tabular}

T A B E L A 3

Percentagens de discordâncias intra examinador classificadas segundo as categorias do Indice INTG, utilizando-se a unidade dente, para $\circ$ Examinador $A$

\begin{tabular}{|c|c|c|c|c|c|c|}
\hline $1 .^{\circ}$ Exame & I & II & III & IV & $\mathrm{V}$ & VI \\
\hline I & 0 & 36,84 & 0 & 3,94 & 0 & 0 \\
\hline II & 19,73 & 0 & 1,31 & 6,57 & 0 & 0 \\
\hline III & 1,31 & 0 & 0 & 11,84 & 0 & 0 \\
\hline IV & 2,63 & 1,31 & 14,47 & 0 & 0 & 0 \\
\hline $\mathrm{v}$ & 0 & 0 & 0 & 0 & 0 & 0 \\
\hline VI & 0 & 0 & 0 & 0 & 0 & 0 \\
\hline
\end{tabular}


CARDOSO, G. M. - Verificação da aplicabilidade e comportamento do indice de Lowell Smith; para estimar as necessidades de.. Rev. Saúde públ., S. Paulo, 3(2):117-132, dez. 1969.

T A B E L A 4

Percentagens de discordancias intra examinador classificadas segundo as categorias do Indice INTG, utilizando-se a unidade dente, para o Examinador $B$

\begin{tabular}{|c|c|c|c|c|c|c|}
\hline $10^{\circ}$ Exame & I & II & III & IV & V & VI \\
\hline I & 0 & 12,67 & 18,30 & 2,81 & 0 & 0 \\
\hline II & 15,49 & 0 & 4,22 & 5,63 & 0 & 0 \\
\hline III & 8,45 & 7,04 & 0 & 5,63 & 0 & 0 \\
\hline IV & 5,63 & 5,63 & 9,85 & 0 & 0 & 0 \\
\hline $\mathrm{v}$ & 0 & 0 & 0 & 0 & 0 & 0 \\
\hline VI & 0 & 0 & 0 & 0 & 0 & 0 \\
\hline
\end{tabular}

T A B E L A 5

Percentagens de discordancias entre examinadores, classificadas segundo as categorias do Indice INTG, utilizando-se a unidade dente

\begin{tabular}{l|cccccc}
\hline & I & II & III & IV & V & VI \\
\hline II & 0 & 19,94 & 14,16 & 5,47 & 0 & 0 \\
III & 15,89 & 0 & 0,57 & 2,89 & 0 & 0 \\
IV & 10,40 & 4,62 & 0 & 8,67 & 0 & 0 \\
V & 5,78 & 0 & 6,93 & 0 & 0 & 0 \\
\hline & 0 & 0 & 0 & 0 & 0 & 0 \\
\hline
\end{tabular}


CARDOSO, G. M. - Verificacão da aplicabilidade e comportamento do indice de Lowell Smith, para estimar as necessidades de.. Rev. Saúde públ., S. Paulo, 3(2):117-132, dez. 1969.

T A B E L A 6

Número de individuos classificados nos pares de categorias para exame e reexame, segundo o Indice INTG, unidade individuo (Examinador $A)^{*}$

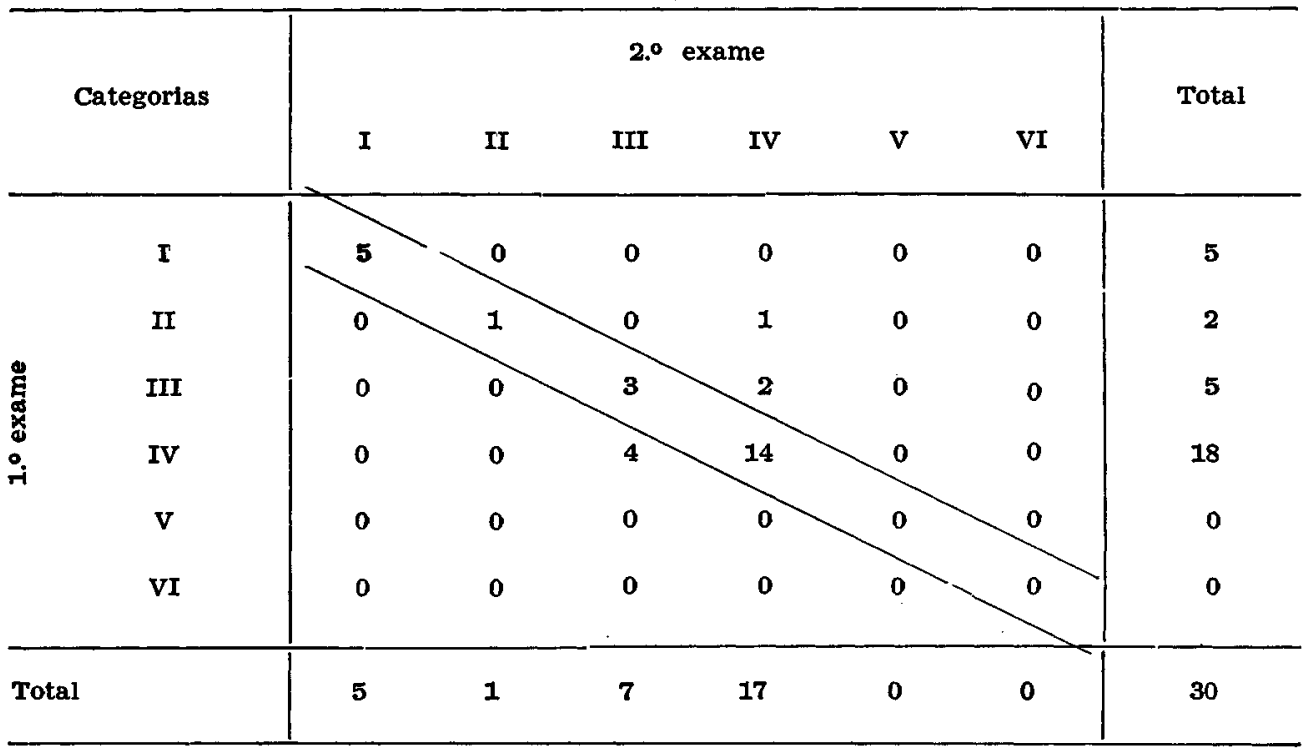

- Os individuos entre as linhas diagonais foram colocados nas mesmas categorias em ambos os exames.

T A B E L A 7

Número de individuos classificados nos pares de categorias para exame e reexame, segundo 0 Indice INTG, unidade individuo (Examinador $B$ )*

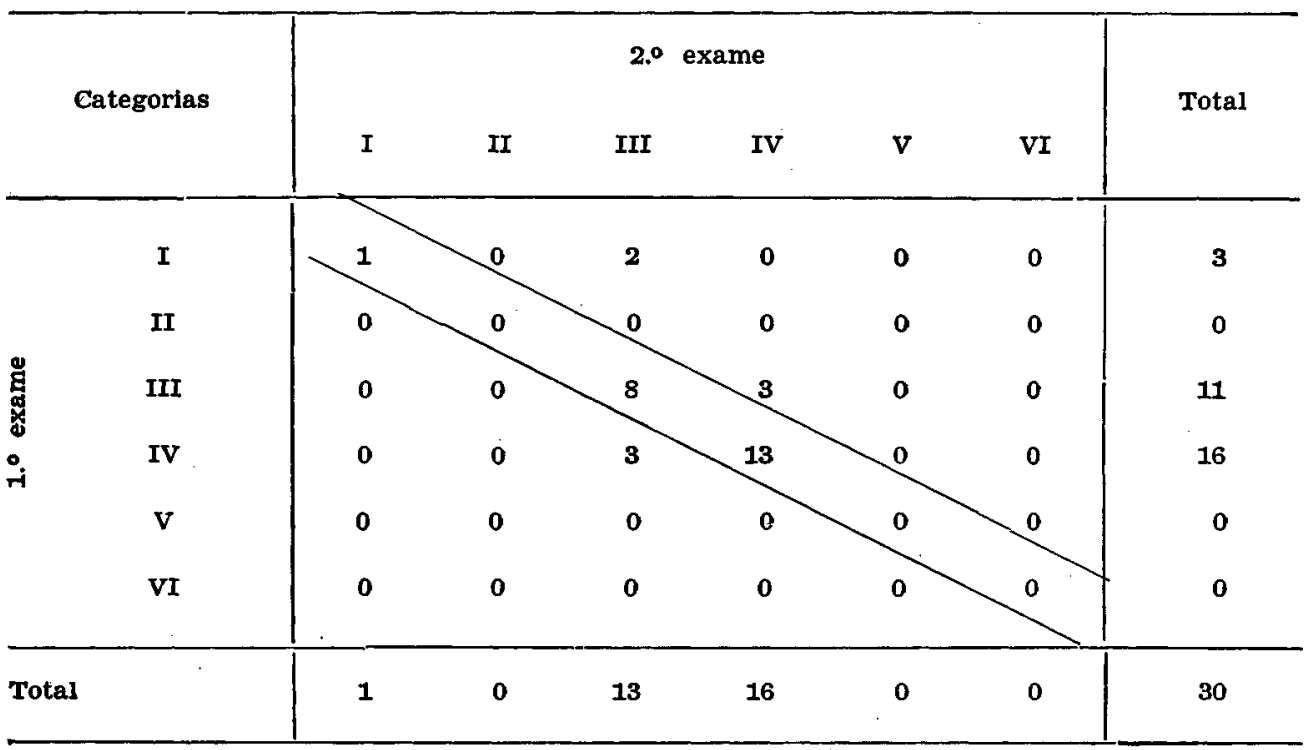

- Os individuos entre as linhas diagonais foram colocados nas mesmas categorlas em ambos os exames. 
CARDoso, G. M. - Verificação da aplicabilidade e comportamento do índice de Lowell Smith, para estimar as necessidades de.. Rev. Saúde públ., S. Paulo, 3(2):117-132, dez. 1969.

T A B E L A 8

Número de indivíduos classificado nos pares de categorias segundo o exame realizado, utilizando-se o indice INTG, unidade indivíduo (Examinadores $A$ e $B$ )*



* Os indivíduos entre as linhas diagonais foram colocados nas mesmas categorias por ambos os examinadores.

TA B E L A 9

Percentagens de discordâncias intra examinadores, quando se utiliza a unidade indivíduo

\begin{tabular}{|c|c|c|c|c|c|}
\hline \multirow{2}{*}{ Tipo de } & \multirow{2}{*}{ Discordâncias } & \multicolumn{2}{|c|}{ N. ${ }^{\circ}$} & \multicolumn{2}{|c|}{$\%$} \\
\hline & & $\mathbf{A}$ & B & $\mathbf{A}$ & $\mathbf{B}$ \\
\hline $\mathbf{I}$ & - III & 0 & 2 & 0 & 25,0 \\
\hline II & - IV & 1 & 0 & 28,6 & $\mathbf{0}$ \\
\hline III & - IV & 2 & 3 & 14,2 & 37,5 \\
\hline IV & - III & 4 & 3 & 57,2 & 37,5 \\
\hline & Total & 7 & 8 & 100,0 & 100,0 \\
\hline
\end{tabular}


CARDoso, G. M. - Verificação da aplicabilidade e comportamento do indice de Lowell Smith, para estimar as necessidades de.. Rev. Saude públ., S. Paulo, $\mathbf{3}(2): 117-132$, dez. 1969.

T A B E L A 10

Percentagens de discordâncias entre examinadores quando se utilizou a unidade individuo

\begin{tabular}{|c|c|c|c|}
\hline $\begin{array}{r}\text { Tip } \\
\text { Discor }\end{array}$ & $\begin{array}{l}\text { o de } \\
\text { dâncias }\end{array}$ & N. $^{\circ}$ & $\%$ \\
\hline I & $-\quad$ II & 1 & $\mathbf{3 , 5}$ \\
\hline I & - III & 1 & 3,5 \\
\hline $\mathbf{I}$ & - IV & 3 & 10,8 \\
\hline II & - & 1 & 3,5 \\
\hline II & - III & 2 & 7,2 \\
\hline II & - IV & 1 & $\mathbf{3 , 5}$ \\
\hline III & - & 1 & $\mathbf{3 , 5}$ \\
\hline III & $-I V$ & 7 & 25,2 \\
\hline IV & - & 1 & 3,5 \\
\hline IV & - & 2 & 7,2 \\
\hline IV & - III & 8 & 28,6 \\
\hline \multicolumn{2}{|c|}{ Total } & 28 & 100,0 \\
\hline
\end{tabular}

\section{DISCUSSAO DOS RESUL'TADOS}

As tabelas que mostram a utilização da unidade-dente foram elaboradas, apenas, em função do treinamento de diagnóstico (Tabelas 2, 3, 4 e 5).

0 que irá interessar, realmente, quando se aplica o Indice INTG num levantamento, é a unidade-indivíduo.

$O$ número de indivíduos, no qual o examinador A discordou, foi de 7. Analisando-se os erros intra verifica-se que existe dificuldade para detecção do cálculo subgengival, pois, além da subjetividade, implica numa grande habilidade $\mathrm{e}$ tato do examinador.
O êrro do tipo III-IV é, pois, um êrro de técnica. Sob o ponto de vista clínico, o que interessa é que o indivíduo não seja prejudicado na sua estimativa de necessidade de tratamento gengival.

Este mesmo examinador errou em $28,6 \%$ para as categorias II e IV. Isto significa que em função da presença de cálculo, o examinador esquece $o$ induto.

0 número de indivíduos no qual o examinador $B$ discordou foi de 8. Observou-se que $37,5 \%$ de discordâncias foram do tipo III-IV (Tabela 9), ocorrendo o mesmo em $14,2 \%$ para o examinador $A$, isto é, houve dificuldade na detecção de cálculo infragengival. $O$ outro êrro cometido por êste examinador foi do tipo II-IV, com uma percentagem de $28,6 \%$ (Tabela 9 ). 0 êrro foi de técnica, pois o examinador $B$, em presença do cálculo, esqueceu o induto. Ainda na Tabela 9, vemos $25 \%$ de discordâncias representando o êrro do tipo I-III, isto é, novamente houve falha na técnica de exame. Pode-se verificar que, tanto para o examinador A como para o B, o problema primordial foi de técnica. Daí, conclui-se que em calibração se deve dar ênfase à técnica para a detecção de cálculo, principalmente do infragengival.

O número de indivíduos, no qual os examinadores discordaram foi de 28 . As maiores percentagens de discordâncias encontradas foram entre as categorias III-IV, num total de 53,8\% (Tabela 10 ). Esta percentagem de discordâncias demonstra dificuldade na detecção de cálculos supra e infragengivais.

Analisaram se os outros tipos de discordâncias entre examinadores (Tabela 10). Observou-se que houve êrro de técnica, por discordâncias na detecção de induto e cálculos supra ou subgengivais, os quais já foram analisados, anteriormente.

Quanto ao êrro de técnica I-II, acreditamos que se utilizarmos uma solução reveladora, êle será eliminado. O clínico, ao examinar indivíduos, deveria ava- 
CARDoso, G. M. - Verificação da aplicabilidade e comportamento do indice de Lowell Smith, para estimar as necessidades de.. Rev. Saúde públ., S. Paulo, 3(2):117-132, dez. 1969.

liar as condições que indiquem maior severidade, e não deter-se, sòmente, nas classificações já assinaladas.

Contràriamente ao Índice de Russell, pode-se observar no fndice de SMrTH ${ }^{25}$ (1966) que a categoria menor é dada à unidade-dente e não ao indivíduo.

Não foram encontrados indivíduos que fôssem classificados entre as categorias $V$ e VI, isto é, não se encontraram indivíduos com cálculo subgengival cobrindo mais de $1 / 3$ da superfície dental (categoria V). Nem indivíduos com problemas periodontais (categoria VI). Isto, talvez, devido ao grupo etário tomado na amostra.

A percentagem de concordâncias encontrada entre examinadores, neste estudo, foi de $70 \%$. $O$ examinador $A$ encontrou $76 \%$ e o examinador B, 73\%. SMith ${ }^{25}$ (1966) encontrou para ambos os examinadores a percentagem de $84 \%$; para o examinador $\mathrm{A}, 85 \%$, e para o B, $83 \%$.

Com a finalidade de se saber a probabilidade dos resultados cairem num determinado intervalo foram calculados os intervalos de confiança para percentagens de discordâncias intra e entre examinadores; o mesmo sucedendo para as percentagens de concordâncias.

\section{CON C L U SOE S}

1. As percentagens de concordância entre examinadores, quando se utilizou a unidade-indivíduo, foi de $70 \%$.

2. Ao se realizarem levantamentos com o Indice INTG, é recomendável que dois examinadores os executem. Dêsse modo a classificação final será mais precisa.

3. Na calibração deve-se dar ênfase à técnica para a detecção do cálculo, principalmente para o subgengival.

4. Quando se utilizou a unidade-indivíduo, as maiores percentagens de dis- cordâncias encontradas foram para a detecção de cálculo supra e subgengivais.

5. Não foram atribuídas a nenhum dos indivíduos examinados as categorias $\mathrm{V}$ ou VI.

6. 0 Indice poderá ser aplicado pois oferece percentagem de concordância bastante satisfatória.

Cardoso, G. M. - Control of applicability and behaviour of Lowell Smith Index to estimate the need for gengival treatment. $R \backsim v$. Saude pribl., S. Paulo, 3(2) :117-132, dez. 1969.

Summary - A study of calibration has been made in students of the "Colégio Estadual Carlos Maximiliano Pereira dos Santos" in São Paulo, Brazil, applying the GTI Index of Lowell Smith that estimates the needs of gengival treatment. The aim of the work to which we have proposed ourselves was to test the GTI INDEX and check, its applicability and effectiveness. The percentage of agreement found beetween examinators was of $70 \%$. For the examinator A $76 \%$ was found, and for the examinator $B$ the agreement was $73 \%$.

\section{REFERENCIAS BIBLIOGRAAFICAS}

1. BERQUÓ, E. S. - Bioestatística. São Paulo, F.H.S.P., Departamento de Estatistica Aplicada, 1967.

2. DAviEs, G. N. - Dental conditions among the polynesians of Pukapuka (Danger Island). The prevalence of periodontal disease. $J$. dent. Res., 35:735-741 , Oct. 1956.

3. ENGLANDER, H. R. - Epidemiology: a fundamental discipline in dental research. J. Amer, dent. Ass., 65:755-762, Dec. 1962.

4. GREENE, J. C. - Epidemiology and indexing of periodontal disease. J. Periodont., 30:133-139, Apr. 1959. 
CARDoso, G. M. - Verificação da aplicabilidade e comportamento do indice de Lowell Smith, para estimar as necessidades de.. Rev. Saúde públ., S. Paulo, 3(2):117-132, dez. 1969.

5. GREENE, J. C. - The eptdemiology of periodontal disease. Abstract presented before the Annual Conference on Advances in Public Health Dentistry, Fresno (Cal.), 1965.

6. GREENE, J. C. - Oral hygiene and periodontal disease. Amer. J. publ. Hith., 53:913-922, June, 1963.

7. GREENE, J. C. \& VERMILLION, J. R. - The oral hygiene index: a method for classifying oral hygiene status. $J$. Amer, dent. Ass., 61:172-179, Aug. 1960.

8. GREENE, J. C. \& VERMILLION, J. R. - The simplified oral hygiene index. J. Amer. dent, Ass., 68:25-31, Jan. 1964.

9. KRESHOVER, S. J. \& RUSSELL, A. L. - Periodontal disease. J. Amer. dent. Ass., 56:529-625, May, 1958.

10. LeVINE, S. - Periodontal disease: a public health prbolem. Aust. dent. J., 10:69-74, Feb. 1965.

11. LILIENTHAL, B.; ARMENA, V. \& GREGORY, G. - An epidemiological study of chronic periodontal disease. Arch. oral Biol., 10:553-566, July/Aug. 1965.

12. LINN, E. L. - Oral hygiene and periodontal, disease: implications for dental health programs. J. Amer. dent. Ass., 71:39-42, July, 1965.

13. Lovdal, A. et al. - Combined effect of subgingival scaling and controlled oral hygiene on the incidence of gingivitis. Acta ondont. scand., 19:537-555, Dec. 1961.

14. MARSHALL-DAY, D. C. - The epidemiology of periodontal disease. J. $\mathrm{Pe}$ riodont., 22:13-22, Jan. 1951.

15. MASSLER, M.; SHOUR, I. \& CHOPRA, B. - Occurence of gingivitis in suburban Chicago School Children. J. Periodont., 21:146-164, 1950.

16. ORGANIZACION MUNDIAL DE LA SALUD - Comité de Expertos en Higiene Dental. Las paradontopatias. Ginebra, 1961. (Ser. inf. técn. 207).
17. PELTON, W. J.; PENNEL, E. H. \& DRUZINA, A. - Tooth morbidity experience of adults. J.Amer. dent. Assoc.. 49:439-455, Oct. 1954 .

18. RAMFJORD, S. P. - Indices for prevalence and incidence of periodontal disease. J. Periodont., 30:51-59, Jan. 1959.

19. RUSSELL, A. L. - Epidemiologia mundial e saúde oral, Odontologia Dinamica, 1:8-20, abr. 1967.

20. RUSSELL, A. L. - Periodontal disease and nutrition in South Vietnam. J. dent. Res., 44:775-782, July/Aug. 1965.

21. RUSSELL, A. L. - A system of classification and scoring for prevalence surveys of periodontal disease. J. dent. Res., 35:350-559, June, 1956.

22. SAXo PAULO (Estado). Universidade. Faculdade de Higiene e Saúde Pública Higiene oral controlada e moléstia perlodontal. São Paulo, 1967. (COS 50/ 67 - mimeografadu).

23. SHEI, O. et al, - Alveolar boneloss as related to oral hygiene and age. J. Periodont., 30:7-11, Jan. 1959.

24. SCHERP, H. W. - Current concepts in periodontal disease research: epidemiological contributions. J. Amer. dent. As8, 68:667-675, Apr. 1964.

25. SMITH, W. L. - The gingival treatment index: a survey method to estimate need and time required for gingival treatment. Denver, Col., State Department of Public Health, Dental Health Section, 1966. (Dados inéditos).

26. VIEGAS, A. R. - Odontologia sanitária: aspectos preventivos. São Paulo, Faculdade de Higiene e Saúde Pública, 1965. (Manual de Odontologia Sanitária, v. 4).

27. WAERHAUG, J. - Epidemiology of periodontal disease. Review of literature. In: WORLD Workshop in Periodontics. Ann Arbor (Mich.), 1966. 